\title{
Da não-tributação das verbas decorrentes de indenizações trabalhistas ${ }^{1}$
}

\author{
Flávia K. Miyasato ${ }^{2}$
}

\begin{abstract}
Resumo
Embora a Constituição ou as leis infraconstitucionais que tratam sobre o Imposto sobre a Renda de Pessoas Físicas não façam previsão da incidência do tributo sobre os valores decorrentes de verbas indenizatórias de natureza trabalhista, o Dec. $\mathrm{n}$ 3000/99, em seu art. 43 dispõe que são passíveis de tributação a licença-prêmio e férias não gozadas transformadas em pecúnia ou indenização. Apesar de Fisco muitas vezes considerar como base de cálculo os valores decorrentes da indenização, os Tribunais têm considerado como inconstitucional tal tributação, pois não são acréscimos patrimoniais decorrentes de renda ou proventos de qualquer natureza, mas sim uma reposição, uma compensação de uma perda ou dano que a pessoa teve, de um direito que por algum motivo ficou impossibilitada de desfrutar. Desta forma, é inconstitucional considerar com base de cálculo os valores advindos de indenizações trabalhistas.
\end{abstract}

Palavras Chave: Imposto sobre a Renda de Pessoas Físicas; Não-tributação; Verbas indenizatórias; Acréscimos patrimoniais.

\section{Introdução}

Em se tratando de tributação sobre a renda de pessoas físicas, cabe verificar se 0 cidadão contribuinte possui a disponibilidade econômica ou jurídica sobre o valor alvo da tributação pelo Fisco.

Além de possuir a disponibilidade, o valor deverá advir de acréscimos patrimoniais de rendas já existentes ou proventos de qualquer natureza, de acordo com o Código Tributário Nacional.

Entretanto, as verbas indenizatórias de natureza trabalhista, uma vez que esses valores são considerados como uma reposição, uma compensação por uma perda ou dano sofrido pela pessoa, não poderão ser objeto de tributação, pois não constituem rendas ou proventos de qualquer natureza, conforme disposto na legislação que trata do Imposto sobre a Renda de Pessoas Físicas e também na Constituição Federal de 1988.

\footnotetext{
${ }^{1}$ Trabalho apresentado como requisito parcial de avaliação da Disciplina de Direito Tributário na Graduação do Curso de Direito pela Universidade Estadual de Londrina.

${ }^{2}$ Graduanda no Curso de Direito pela Universidade Estadual de Londrina. flavia_miyasato@yahoo.com.br
}

Revista de Direito Púbuco, Londrina, V. 3, N. 2 P. 74-83, m Al/ Ago. 2008. 
Apesar da previsão constitucional sobre o que são proventos e de que as verbas decorrentes de indenizações trabalhistas não estarem incluídos neste tipo de rendimento, 0 Fisco insiste em considerar como objeto de tributação as férias e licenças prêmios não gozadas e transformadas em pecúnia ou indenização, entre outros direitos transformados em indenização.

Isto ocorre por haver previsão no Regulamento do Imposto de Renda, ato administrativo do Poder Executivo, o qual pode ter força de lei, mas não poderá contrariá-la e nem aumentar ou diminuir a sua incidência.

Levando a discussão para a análise do Poder Judiciário, os Tribunais estão respeitando a Lei Maior e considerando tal tributação indevida e, mais ainda, inconstitucional, devolvendo o valor cobrado indevidamente do cidadão.

\section{Noções gerais sobre o imposto de renda}

O Imposto sobre a Renda e Proventos de Qualquer Natureza, é o tributo previsto no art. 153, inciso III, da Constituição Federal de 1988, o qual prevê:

"Compete à União instituir impostos sobre:

III - rendas e proventos de qualquer natureza."

Do referido artigo, observa-se que a regra-matriz constitucional é o imposto sobre a renda e proventos de qualquer natureza.

0 critério material consiste em auferir renda e proventos de qualquer natureza. Seu critério temporal vai ser o momento da aquisição da disponibilidade econômica ou jurídica, previsto no art. 43 do CTN. Seu critério espacial vai ser a aquisição da disponibilidade pelo contribuinte residente e domiciliado dentro do território nacional, elencados no art. 20 do Dec. no 3000/99. A base de cálculo é o montante, real, arbitrado ou presumido, da renda ou proventos de qualquer natureza tributáveis, de acordo com o art. 44 do CTN. Já alíquota será progressiva, determinação constitucional prevista no art. 153, III, § 2o, I, observando-se 0 caráter pessoal e graduando-se conforme a capacidade econômica (contributiva) do contribuinte.

Seguindo a Lei Maior, e complementando-a, o Código Tributário Nacional, Lei no 5172/66, dispõe em seu art. 43: 
0 imposto, de competência da União, sobre a renda e proventos de qualquer natureza, tem como fato gerador a aquisição da disponibilidade econômica ou jurídica:

I - de renda, assim entendido o produto do capital, do trabalho, ou da combinação de ambos;

II - de proventos de qualquer natureza, assim entendidos os acréscimos patrimoniais não compreendidos no inciso anterior.

A competência dada pela Carta Magna, para instituir e exigir o tributo, é da União Federal, sendo esta o sujeito ativo da relação jurídica tributária. Esta competência tributária é privativa da pessoa política de direito interno, no caso a União, sendo indelegável para outros entes federativos.

Cabe salientar que o Imposto sobre a Renda e Proventos de Qualquer Natureza é 0 de maior arrecadação no âmbito da União, sofrendo modificações em sua legislação no decorrer do tempo, sendo periodicamente editados decretos regulamentares consolidando as alterações legais.

0 atual regulamento é o Decreto $\mathrm{n}-3000 / 99$, mais conhecido como Regulamento do Imposto de renda (RIR). Comporta três divisões, quais sejam:
a) tributação das pessoas físicas (Livro I, arts. 10 a 145);
b) tributação das pessoas jurídicas (Livro II, arts. 146 a 619;
c) tributação na fonte e sobre operações financeiras (Livro III, art. 620 a 786).

Entretanto, a tributação das pessoas físicas é regulada pela lei № 9250/95, a qual trata sobre o Imposto de Renda das Pessoas Físicas (IRPF). Saliente-se que as normas gerais estão previstas no CTN, enquanto as normas ordinárias são editadas para facilitar sua aplicação.

Como sujeito ativo, a União tem o direito subjetivo de exigir o cumprimento da obrigação tributária do sujeito passivo, o qual tem o dever de cumpri-la.

O sujeito passivo da relação jurídica tributária, uma vez que é atingido pela hipótese de incidência tributária, vai ser aquele que, no caso do Imposto sobre a Renda de Pessoas Físicas, auferir/adquirir rendas e proventos de qualquer natureza, sendo o fato gerador deste tributo, a aquisição de disponibilidade econômica ou jurídica de tais rendas e proventos de qualquer natureza. 
O sujeito passivo da relação jurídica tributária será o cidadão contribuinte elencados no art. 2ำ do Regulamento do Imposto de Renda, os quais são possuidores de disponibilidade econômica ou jurídica de rendas e proventos de qualquer natureza.

\section{Conceito de renda e proventos de qualquer natureza:}

De acordo com o Código Tributário Nacional, em seu art. 43, I, entende-se por rendas o produto do capital, do trabalho ou da combinação de ambos.

Embora não haja consenso sobre o conceito de renda, tanto na teoria econômica quanto na teoria jurídica, pode-se dizer que a renda como expressão jurídico-tributária consiste no acréscimo patrimonial, expressando conteúdo de riqueza, incremento ao patrimônio do sujeito. Porém, só se pode falar em renda se houver possibilidade de quantificá-la, uma vez que "o direito tributário trabalha com fatos, circunstâncias de fato ou situação jurídica de conteúdo econômico" (CASSONE, 2004. p. 370). É possível ainda afirmar que "a renda está relacionada à aferição durante certo período de tempo, e num acréscimo patrimonial" (CASSONE, 2004. p.371).

Os proventos de qualquer natureza, de acordo com o Código Tributário Nacional, em seu art. 43, inciso II, entende-se que são os acréscimos patrimoniais não compreendido no inciso anterior (produtos do capital, do trabalho ou da combinação de ambos).

Já a Constituição Federal, em seu art. 40, trata dos proventos como: a) da aposentadoria por invalidez; b) da aposentadoria compulsória; c) da aposentadoria por tempo de serviços; d) da aposentadoria por idade; e) da pensão por morte do servidor falecido; f) das aposentadorias e pensões dos "Servidores Públicos Militares" (art. 40 da CF), diferenciando, ainda, no $\S 5$, o benefício da pensão por morte quando decorrente de vencimentos, quando houver falecimento do servidor na ativa e proventos, do servidor falecido na aposentadoria. A Constituição ainda faz distinção entre proventos de aposentadorias e pensão (dos servidores públicos civis e militares), dos benefícios previdenciários (dos trabalhadores do setor privado - arts. 8a 201).

Percebe-se, então, que a renda e os proventos de qualquer natureza são constituídos de acréscimo. Sem o acréscimo patrimonial, segundo o Código Tributário Nacional, não há renda e nem tampouco proventos.

Mas, indaga-se, do que são constituídos os acréscimos patrimoniais? 
Estando intimamente ligado à renda, os acréscimos patrimoniais são os valores ganhos que superam o mínimo que uma pessoa necessita para sobreviver, existindo a partir deste valor a possibilidade de a renda ser tributada, pois o mínimo vital para a subsistência do contribuinte não pode ser tributado, estando assim isentos.

\section{Disponibilidade econômica e disponibilidade jurídica}

Ao adquirir a renda ou proventos de qualquer natureza, a pessoa precisa ter a disponibilidade econômica ou jurídica para ser considerada contribuinte, pois será atingida pela hipótese de incidência tributária, havendo o fato gerador do imposto de renda.

A disponibilidade econômica, segundo Hugo de Brito Machado (2003, p. 434):

Entende-se como disponibilidade econômica a possibilidade de dispor, possibilidade de fato, material, direta, da riqueza. Possibilidade de direito e de fato, que se caracteriza pela posse livre e desembaraçada da riqueza. Configura-se pelo efetivo recebimento da renda ou dos proventos.

E a disponibilidade jurídica:

[...] configura-se, em princípio, pelo crédito das rendas ou dos proventos. Enquanto a disponibilidade econômica corresponde ao rendimento realizado, a disponibilidade jurídica corresponde ao rendimento (ou provento) adquirido, isto é, ao qual o beneficiário tem título jurídico que lhe permite obter a respectiva realização em dinheiro.

Para Marilene Talarico Martins Rodrigues (2001, p. 311), citando o entendimento do Plenário do XI Simpósio Nacional de Direito Tributário:

Aquisição de Disponibilidade Econômica de renda e proventos de qualquer natureza é a obtenção da faculdade de usar, gozar ou dispor de dinheiro ou coisa nele conversíveis, entrados para o patrimônio do adquirente por ato ou fato jurídico (maioria).

Aquisição de Disponibilidade Jurídica de renda e proventos de qualquer natureza é a obtenção de direitos de créditos, não sujeitos à condição suspensiva.

Então, do exposto acima, não basta que a renda ou provento de qualquer natureza entre no patrimônio da pessoa, mas necessariamente que a renda esteja disponível jurídica ou economicamente para ser tributável, tornando-se objeto da tributação pelo imposto de 
renda.

\section{Da não tributação pelo imposto de renda nas indenizações trabalhistas}

Embora não esteja expressamente disposto na Constituição ou nas legislações infraconstitucionais, as verbas decorrentes de indenizações trabalhistas não são tributáveis.

Para ser tributável, a renda precisa ser um acréscimo ao patrimônio da pessoa decorrente de seu trabalho, ganhos de capital, ou de ambos.

Com as verbas indenizatórias trabalhistas não há acréscimo decorrente do trabalho, do ganho de capital ou de ambos juntos, mas sim uma reposição de algo que a pessoa perdeu ou deixou de ganhar.

O próprio Superior Tribunal de Justiça já tratou do assunto na Súmula 125: "O pagamento de férias não gozadas por necessidade do serviço não está sujeita à incidência do Imposto de Rena, Súmula 136, a qual dispõe: "O pagamento de licença-prêmio não gozada por necessidade do serviço não está sujeito ao Imposto de Renda", assim como a Súmula 215: "A indenização recebida pela adesão ao programa de incentivo à demissão voluntária não está sujeito à incidência do imposto de renda".

Entretanto, apesar de não ser tributável, os valores decorrentes deste tipo de indenização muitas vezes são tributadas do cidadão pela Receita Federal, pois o entendimento do Fisco, conforme opinião de Ives Gandra da Silva Martins (2000, p. 194) em seu parecer, é de que:

1) 0 art. 43 do CTN, apesar de referir-se à disponibilidade econômica, em verdade teria pretendido referir-se à "acréscimo patrimonial";

2) 0 art. 60 , V , da Lei 7.713 referir-se-ia a uma isenção e não a uma "nãoincidência", de tal forma que as diversas formas de indenizações trabalhistas teriam limites na lei;

3) 0 art. 111 do CTN não permitiria interpretações extensivas da norma de isenção; 4) não procedendo à retenção do imposto de renda, a fonte pagadora seria apensa solidária ao verdadeiro responsável pela contribuição, ou seja, o contribuinte; 5) há decisões administrativas a favor do entendimento oficial.

Apesar de haver inúmeras decisões judiciais contrárias ao posicionamento adotado pelo Fisco, tais como se pode citar os julgados do Tribunal Regional Federal da 4a Região, na A pelação Cível, com decisão do dia 24/10/2006, da Segunda Turma julgadora, processo no 2005.70.00.002577-0, Relator Leandro Paulsen:

TRIBUTÁRIO - APELAÇÃO - ABONO DE FÉRIAS NÃO GOZADAS - NÃO INCIDÊNCIA DO IMPOSTO DE RENDA. 1. Férias não-gozadas não configuram acréscimo patrimonial 
de qualquer natureza ou renda e sua conversão em pecúnia caracteriza compensação (indenização) pela impossibilidade de sua fruição. 2. 0 adicional de $1 / 3$ (um terço) sobre as férias não está sujeito à incidência de imposto de renda. 3 . A conversão em pecúnia destes benefícios, independente do motivo, não altera sua natureza jurídica indenizatória, não cabendo incidência do IRPF.

No mesmo sentido a decisão da Apelação Cível, Relatora Maira Lúcia Luz Leiria, Primeira Turma, decisão do dia, processo: 2002.72.00.008872-1:

TRIBUTÁRIO - APELAÇÃO - FÉRIAS VENCIDAS E NÃO GOZADAS - NÃO INCIDÊNCIA DO IM POSTO DE RENDA. 1. Férias é benefício de nítido caráter indenizatório. 2. A conversão em pecúnia destes benefícios, independente do motivo, não altera sua natureza jurídica, não cabendo incidência do IRPF.

Assim como posição do Tribunal Regional Federal da 3ạ Região, no julgado do dia 20/10/2004, processo no 1999.03.99.068655-8, julgado pela TERCEIRA TURM A:

DIREITO CONSTITUCIONAL. TRIBUTÁRIO. IRPF. LICENÇA-PRÊMIO. FÉRIAS CONVERTIDAS EM PECÚNIA. LANÇAM ENTO NA DECLARAÇÃO COM O RENDIM ENTO NÃO TRIBUTÁRIO. REVISÃO. GLOSA. INCLUSÃO NA BASE DE CÁLCULO. NATUREZA JURÍDICA DA VERBA. INDENIZAÇÃO. NECESSIDADE DE SERVIÇO INERENTE AO NÃOGOZO IN NATURA DO DIREITO. PRESUNÇÃO DE PREVALÊNCIA DO INTERESSE PÚBLICO. 1. Não incide imposto de renda sobre as pecúnias de férias e licençaprêmio, resultado da conversão em INDENIZAÇÃo da supressão da prerrogativa legal de gozo in natura do direito de afastamento provisório e remunerado do serviço ativo, estando presumido, pelo ato administrativo de deferimento da conversão, a necessidade de serviço, suficiente para legitimar a aplicação das Súmulas 125 e 136 do Superior Tribunal de Justiça. 2. Caso em que os valores foram declarados como rendimentos não-tributáveis, tendo o Fisco efetuado a glosa em revisão e lançamento de ofício, apurando saldo de imposto a pagar, ao invés de imposto a restituir, como constou da declaração elaborada pelo contribuinte: restabelecimento do lançamento originário, exclusão das verbas da base de cálculo do IRPF. 3. Apelação desprovida, sentença confirmada.

Apesar de 0 art. 43 do Regulamento do Imposto de Renda, em seus incisos II e III preverem que são tributáveis os rendimentos provenientes de férias e licenças-prêmios transformadas em pecúnias ou indenizadas, como se percebe, os tribunais atendendo aos princípios constitucionais de que as férias e licenças-prêmios são direitos do trabalhador e que se não forem gozadas devidamente, deverão ser indenizadas pela impossibilidade de sua fruição e, mesmo sendo convertidos em pecúnias, não altera sua natureza jurídica, as quais entrando para o patrimônio do cidadão, não deverão servir de base de cálculo para a tributação pelo Fisco, porque não é um acréscimo patrimonial decorrente de seu trabalho, 
mas indenização por um direito não gozado, um descanso que é merecido, mas que não foi fruído pelo contribuinte trabalhador.

Citando palavras de Wanderley José Federighi (2000, p. 80):

É consenso na jurisprudência que as verbas integrantes de indenização não podem ser oneradas com a incidência de desconto relativo ao Imposto de Renda. $E$ isto por uma simples razão: a indenização equivale à recomposição do patrimônio do sujeito, titular do direito, que dele se vê privado por razões alheias à sua vontade.

A despedida sem justa causa também gera indenizações trabalhistas, as quais também não deverão ser tributadas, como se pode observar da decisão a seguir do Tribunal Regional Federal da 3a Região:

Classe: AM S - APELAÇÃO EM MANDADO DE SEGURANÇA Processo: 95.03.091923-1, UF: SP, Órgão Julgador: SEXTA TURM A, Data da Decisão: 10/06/1996.

TRIBUTARIO. INDENIZAÇÃO. VERBAS RESCISORIAS ESPECIAIS. NÃO INCIDENCIA DO IRPF. AUSENCIA DE ACRESCIMO PATRIM ONIAL. I - INDENIZACCÃO, ALEM DE SER UM REQUISITO PARA EXERCICIO DE UM DIREITO, TEM POR FINALIDADE A RECOM POSIÇÃO PATRIM ONIAL. DESTARTE, AUSENTE O ACRESCIMO PATRIM ONIAL, NÃO PODE INCIDIR SOBRE A MESMA QUALQUER IMPOSTO. II - VERBAS RESCISORIAS ESPECIAIS, NÃO ESTABELECIDAS EM LEI, RECEBIDAS PELO TRABALHADOR QUANDO DA EXTINÇÃO DO CONTRATO DE TRABALHO POR DISPENSA INCENTIVADA, TEM CARATER INDENIZATORIO, NÃO ENSEJANDO ACRESCIMO PATRIM ONIAL, NÃO SE PODENDO, DAI, FALAR EM INCIDENCIA DO IRPF SOBRE AS MESM AS. III - APELAÇÃO E REMESSA OFICIALIM PROVIDAS.

O ilustre Ives Gandra da Silva M artins (2000, p. 196-197) elucida:

É que as indenizações trabalhistas lato sensu [...] são todas contrapartidas da perda da capacidade profissional para a aquisição de disponibilidade econômica ou jurídica. Não acrescem senão provisoriamente o patrimônio, que é, automaticamente, desprovido da capacidade de seu detentor de gerar renda, mesmo quando a geração é compensatória de não utilização de direito (licençasprêmios, férias não gozadas, etc.).

A própria expressão "indenização" demonstra que quem a recebe, o faz em virtude da perda de algo cujo valor é dimensionado naquele pagamento compensatório.

Segundo o pensamento do ilustre autor, a indenização está fora da competência da União por não ser renda, pois não é aquisição de disponibilidade, mas sim uma compensação pela perda da capacidade de adquirir a disponibilidade que existia antes do evento que causou a indenização e não constituirá a renda, a qual é resultante de um 
acréscimo contrabalançado por decréscimos de naturezas variadas ou, melhor dizendo, "resultando de disponibilidade que se adquire e que deve ser oferecida à tributação" (MARTINS, 2000, p. 197).

Já para a indenização por demissão voluntária também enseja indenização trabalhista e não deverá ser tributada, não devendo ficar retida na fonte.

A natureza da verba indenizatória no Programa de Demissão Voluntária é tipicamente de reposição, de compensação por algo que o trabalhador perdeu e que foi diminuído do seu patrimônio, não resulta de enriquecimento.

Essas verbas visam a diminuir os prejuízos a que estarão sujeitos os trabalhadores quando estes tiverem seu contrato de trabalho extinto.

Para M arcelo M artins Motta Filho (2004, p. 34-35):

A indenização tem dupla finalidade: ressarcir o dano causado e, ao menos em parte, propiciar meios para que o trabalhador que aderiu ao PDV enfrente as dificuldades iniciais, como a procure de emprego ou outro modo de subsistência.

E prossegue seu raciocínio:

Deve-se lembrar que a indenização em comento é fruto de um acordo entre as partes quanto ao término do vínculo empregatício, pelo que é lícito, a par de lógico, deduzir que o direito à referida verba somente resulta da dispensa do empregado de sua atividade laboral.

É uma vantagem em pecúnia paga somente quando o trabalhador se desliga voluntariamente, resultando ainda de acordo entre ele e o empregador, que pagará espontaneamente os valores oferecidos a título de indenização para o empregado privado do seu trabalho e se não trabalhar, não vai receber o salário, e se não tem este rendimento, não é passível de tributação. Logo não poderá servir de base de cálculo para o imposto de renda.

\section{Conclusão}

As verbas indenizatórias trabalhistas, como visam a reparar uma perda, um dano sofrido pela pessoa, não é passível de tributação. Não poderá o Fisco tributar 0 valor recebido a título de indenização, considerando-o como base de cálculo para o Imposto de 
Renda, pois não há um acréscimo patrimonial a título de renda ou proventos de qualquer natureza do seu trabalho ou de ganho de capital ou de ambos.

Apesar de haver previsão no Regulamento do Imposto de Renda, este por ser ato administrativo geral e normativo, destinado a regulamentar uma lei, assemelhando-se a ela, mas sendo ato inferior, não pode contrariá-la, assim como restringir ou ampliar o que estiver disposto nela.

Uma vez que a indenização não está prevista como renda ou proventos de qualquer natureza na Lei Maior, no Código Tributário Nacional e na própria Lei no 9250/95, que trata do Imposto sobre a Renda de Pessoas Físicas, é inconstitucional a previsão do art. 43 do Dec. no 3000/99, ao dispor que são passíveis de tributação as férias e licenças-prêmios convertidas em pecúnia ou indenizadas, prevendo como hipótese de incidência tributária, criando novo fato gerador de tributo.

Caberá ao Poder Judiciário continuar respeitando e fazendo valer o que está disposto na Constituição, considerando não tributáveis as verbas indenizatórias de natureza trabalhista, devolvendo-as aos cidadãos quando forem tributadas indevidamente.

\section{Referências}

FEDERIGHI, Wanderley José. A incidência do imposto de renda sobre o pagamento de férias e licença-prêmio em pecúnia. Revista Tributária e de Finanças Públicas. São Paulo. Ano 8. n. 31.p. 79-83. mar-abril de 2000. Revista dos Tribunais.

FILHO, M arcelo M artins Motta. Da não-incidência do imposto de renda na fonte no programa de demissão voluntária - PDV. Revista Tributária e de Finanças Públicas. Ano 12. n. 59.p. 30-40. nov-dez de 2004. São Paulo: Revista dos Tribunais.

M ACHADO, Hugo de Brito. Comentários ao Código Tributário Nacional. São Paulo: Atlas. 2003.

M ARTINS, Ives Gandra da Silva. Indenizações trabalhistas, quaisquer que sejam, não constituem base de cálculo para o imposto sobre a renda. In Revista Tributária e de Finanças Públicas. Ano 8. n. 33.p. 193-206. jul-ago de 2000. São Paulo: Revista dos Tribunais.

RODRIGUES, M arilene Talarico M artins. In Curso de Direito Tributário. M ARTINS, Ives Gandra da Silva. Curso de Direito Tributário. 8a ed. São Paulo: Saraiva. 2001. 